Article

\title{
Performance and Applicability of Water Column Correction Models in Optically Complex Coastal Waters
}

\author{
Ele Vahtmäe *, Tiit Kutser and Birgot Paavel \\ Estonian Marine Institute, University of Tartu, Mäealuse 14, 12618 Tallinn, Estonia; tiit.kutser@sea.ee (T.K.); \\ Birgot.Paavel@ut.ee (B.P.) \\ * Correspondence: Ele.vahtmae@sea.ee; Tel.: +372-6718946
}

Received: 29 April 2020; Accepted: 4 June 2020; Published: 8 June 2020

check for updates

\begin{abstract}
Maps of submerged aquatic vegetation (SAV) are of primary importance for the sustainable management of coastal areas and serve as a basis for fundamental ecological studies. Various water column correction (WCC) models are successfully applied in clear Case-1 waters to compensate for the variable water depth effect. The performance of the WCC in less clear Case- 2 waters is rarely assessed. In this study, the performance and applicability of model-based WCC algorithms in the complex Baltic Sea were analyzed. The bottom reflectance was retrieved from the Compact Airborne Spectrographic Imager (CASI) water surface reflectance by applying the Maritorena and Lee WCC algorithms. The Maritorena model retrieved bottom spectra that showed large variations in reflectance magnitudes. The Lee model was more successful in retrieving reasonable spectral magnitudes, although only in a rather narrow wavelength region $(550-600 \mathrm{~nm})$. Shorter and longer spectral regions were significantly overcorrected, resulting in unrealistic spectral shapes. Sensitivity analysis indicated that slight under- or overestimation of water depth and water column constituents affect retrieval of correct bottom spectra in Case- 2 waters. To assess the performance of WCC models in improving the SAV quantification, the surface reflectance, as well as the retrieved bottom reflectance, were correlated with the corresponding in situ estimated SAV percent cover (\%SAV). Although the quality of the Lee WCC model was not considered high, the spectral region least affected by the input parameters variations (550-600 nm) can be used for the SAV quantification. Application of the Lee model provided better results in \%SAV assessment than not performing the WCC correction.
\end{abstract}

Keywords: water column correction; Case-2 water; CASI; submerged aquatic vegetation

\section{Introduction}

Remotely sensed hyperspectral data can provide significant knowledge to study submerged aquatic vegetation (SAV) inhabiting marine coastal environments. Maps of the SAV distribution are of primary importance for various management purposes and they also serve as a basis for fundamental ecological studies. Unsupervised and supervised image classification techniques are the most frequently used methods to retrieve SAV spatial distribution and habitat composition maps [1-8]. These methods mostly utilize differences in the water surface reflectance to classify SAV into various broad vegetation and/or benthic substrate classes.

Aside from assessing the extent and spatial distribution of SAV, other parameters are needed for the coastal benthic vegetation related studies and monitoring purposes. Regularly updated and accurate information on SAV abundance is an essential component of the knowledge required for the sustainable management of coastal areas [9]. Moreover, SAV abundance is an important factor indicating the productivity of the benthic ecosystem [10,11]. Abundance can be quantified with different biophysical parameters, such as SAV percent cover (\%SAV), biomass, leaf area index (LAI), etc. 
Different approaches have been used for the assessment of SAV abundance from remotely sensed images [12]. First, an image classification approach may be used, where classes with various levels of $\%$ SAV, LAI or biomass amount are used instead of species/substrates classes [3,13-16]. In this case, in situ measured values of SAV biophysical parameters serve as the training areas in the classification procedure. As discrete thematic classes (such as low, medium or high density) are retrieved as a result of the classification, these methods lack ability to provide continuous SAV abundance maps. Secondly, an empirical method can be used, where the relationship between in situ observed biophysical parameter and image reflectance is established. The resultant empirical relationship is then applied to the entire image, producing a continuous map of SAV abundance [17-22]. Finally, more complex radiative transfer-based methods, also called as physics-based methods, are used in lesser extent for SAV quantification [23,24].

The spectral signal reflected back from the water bottom is modified by the overlaying water column influence, so that the surface reflectance is derived from the combination of bottom reflectance and the optical properties of the water column [25]. This distortion is dependent on the water column optical properties and water depth-the greater the water depth, the more water column constituents dominate the surface signal and the less information about the bottom characteristics can be extracted from the water surface spectra. The benthic contribution is also dependent on the magnitude of bottom reflectance as brighter substrates (such as sand, low density vegetation) contribute more to the surface reflectance than darker substrates (such as high density vegetation). As a result, different bottom features at different water depth may have similar spectral signals. For example, brighter substrates at greater depths may resemble to darker substrates at lesser depths. Therefore, the quantification of SAV abundance requires removal of the overlying water column influence to compensate for the variable water depth effect.

A variety of approaches have been proposed to remove absorption and backscattering effects of the water column. Reference [26] provided a comprehensive overview of proposed methods and suggested to group them accordingly: (1) band combination algorithms, (2) optimization/matching algorithms and (3) model-based algebraic algorithms. Band combination algorithms do not require measurements of water column optical properties, nor bathymetry data from the study area. However, rather than predicting the real bottom reflectance, the band combination algorithms produce a single depth-invariant bottom index from each pair of spectral bands [27-29]. These algorithms can generally be applied to multispectral sensors and require higher water transparency [26,29]. Optimization/matching algorithms require bottom spectra to simulate the water surface spectral library, where water column influence at various depths is added to the bottom spectra. As such, the simulated spectral library represents a database of different combinations of bottom types, water depths and water properties that can then be matched to the remotely sensed spectra $[2,30,31]$. The shortcoming of this method is that all types of substrate reflectance in all possible combinations occurring at the scene must be accurately presented in the model [26]. Finally, model-based algebraic algorithms can be used to retrieve bottom spectra from water surface reflectance spectra $[32,33]$. However, these algorithms require measurements of the water column optical properties, as well as availability of bathymetry data.

The majority of the water column correction (WCC) studies have been successfully applied in the clear and shallow Case-1 coastal waters [18,29,34-37]. The performance of WCC in less clear Case-2 waters has been rarely assessed and reported [22,38]. Optically complex waters attenuate light in greater extent when compared to clear waters, obscuring the retrieval of bottom information and increasing the need for the WCC. However, the success of accurate substrate spectral retrieval in Case- 2 waters is more dependent on the accuracy and precision of the reflectance, attenuation and depth measurements than it is in clear waters [39]. In the current study, the performance, limitations and applicability of model-based algebraic algorithms proposed by Maritorena [32] and Lee [33] were assessed in the complex Baltic Sea waters. Specific objectives include: (1) retrieving bottom reflectance spectra and assessing the quality of WCC in the complex Baltic Sea waters; (2) assessing the sensitivity 
of WCC models to model parameters, such as water depth and concentrations of optically active water color constituents; (3) evaluating the benefits of WCC in SAV abundance quantification.

\section{Materials and Methods}

\subsection{Study Site}

The study site that lies off the northwestern coast of Estonia, in the Gulf of Finland within the Baltic Sea, encompasses two islands-Great Pakri (western island) and Small Pakri (eastern island) (Figure 1). Shallow water $(<3 \mathrm{~m})$ is found near the coast of the mainland and in the narrow strait between the islands. The shallow sandy Kurkse Strait separates the islands from the mainland in south. The deeper Paldiski Bay $(>20 \mathrm{~m}$ ) separates the islands from the mainland on the east. Exposed limestone cliffs are characteristic to the northern coasts of both islands and water depth increases rapidly in the area. In the past, the Soviet air force used the area around the Pakri islands as a military training site. Bomb craters can still be observed on the ground and in the shallow sea bottom. Today, the area belongs to the European network of protected areas (Natura 2000), designated for the protection of natural habitats and species.



Figure 1. (a) Location of the study area in the northwestern coast of Estonia, in the Gulf of Finland within the Baltic Sea; (b) Compact Airborne Spectrographic Imager (CASI) mosaic from the study area.

As relatively shallow sandy areas are widespread in the Pakri study site, the water quality may be influenced by strong winds, which resuspend fine sand particles into the water column. Consequently, the water transparency may be substantially reduced. Two rivers flow into the shallow marshy area in the southeastern part of Paldiski Bay. As higher concentrations of dissolved organic matter flow into the sea through the marsh, this area can be observed as more brownish in the image (Figure 1). Three ports are located in the study area: the small Kurkse port for pleasure boating and the Paldiski southern and northern harbors for cargo and passengers transport. The activity in the ports may affect the water quality in the region to some extent (shipping, dredging, etc.).

\subsection{Airborne Remote Sensing}

Airborne remote sensing data were collected on 31 May 2016 using the Compact Airborne Spectrographic Imager (CASI-1500, Figure 1b). The data collection, as well as radiometric correction and geocorrection, was conducted by the Latvian Institute for Environmental Solutions (IES). Data were collected with 12 separate flight lines covering approximately $60 \mathrm{~km}^{2}$ and mosaicked together in the subsequent image processing. The spatial resolution of the collected images was $1 \mathrm{~m}$. A total of 93 spectral bands in the spectral range of 367-1045 nm were used for the data collection. CASI bandwidths are programmable, which allow optimizing the signal-to-noise ratio (SNR) across the 
entire spectrum. Five nm bandwidths were used for the 550-750 $\mathrm{nm}$ spectral region (higher SNR) and $10 \mathrm{~nm}$ bandwidths were used for the blue and near infrared (NIR) spectral regions (lower SNR).

ENVI (Environment for Visualizing Images, Harris Geospatial Solutions, Inc.) digital image analysis software was used in the following image processing. First, the atmospheric correction was performed by applying the FLAASH (fast line-of-sight atmospheric analysis of spectral hypercubes) atmospheric correction procedure. Water surface reflectance spectra were acquired as a result of FLAASH processing. Secondly, the minimum noise fraction (MNF) method was applied to the atmospherically corrected imagery to reduce the inherent noise of hyperspectral data. Then, a glint correction method proposed by [40] was applied to remove sun glint effect. Finally, land areas were masked out of the image using the CASI NIR spectral region, as this region allows the highest delineation between land and water, based on the different signal strength.

\subsection{In Situ Field Sampling}

\subsubsection{Water Column Optical Properties}

Water column optical properties were measured at four field stations around the Pakri islands on the same day as the CASI image collection (Figure 1). Depth profiles of downwelling spectral irradiance $\left(E_{\mathrm{d}}, \mathrm{W} \mathrm{m}^{-2} \mathrm{~nm}^{-1}\right)$ were collected with the TriOS Ramses spectroradiometer, which is equipped with up to 191 bands covering a wavelength range from 320 to $950 \mathrm{~nm}$. $E_{\mathrm{d}}$ spectra were measured at different depths between 0 and $2.5 \mathrm{~m}$ with a depth resolution of $\sim 50 \mathrm{~cm}$. Multiple measurements were performed at each depth and an average spectrum calculated.

A package of optical instruments containing a Wetlabs ACS, Wetlabs ECO-VSF3 and Seabird Electronics CTD was employed at each field station to provide absorption coefficients, backscattering coefficients, temperature, salinity and pressure data. Due to technical problems, measurements were managed to perform only at the first three field stations (St01-St03, Figure 1). Nonwater absorption coefficients were measured using the Wetlabs ACS instrument. Pure seawater absorption coefficient was taken from [41]. Finally, the total absorption coefficients $\left(a, \mathrm{~m}^{-1}\right)$ were calculated by the sum of nonwater and pure seawater absorption coefficients. Total backscattering coefficients $\left(b_{b}, \mathrm{~m}^{-1}\right)$ were determined with the ECO-VSF3, which measures the volume scattering function at three angles (100, 125 and 150 degrees) and three wavelengths (470, 530 and $660 \mathrm{~nm}$ ), and allows calculation of the particulate backscattering coefficient through interpolation between the measured angles. The value of pure seawater backscattering coefficient was taken from [42].

Water samples were collected from the surface layer (top $0.5 \mathrm{~m}$ ) for each field station visited. Samples were analyzed for the concentrations of optically active water color constituents: chlorophyll a $\left(\mathrm{Chl}-\mathrm{a}, \mathrm{mg} \mathrm{m}^{-3}\right)$, colored dissolved organic matter $\left(\mathrm{aCDOM}, \mathrm{m}^{-1}\right)$ and total suspended matter (TSM, $\mathrm{g} \mathrm{m}^{-3}$ ). Laboratory analyses are described in more detail in [43].

\subsubsection{Benthic Information Collection}

Aerial photographs from the public web map application of the Estonian Land Board (https: //xgis.maaamet.ee/xgis2/page/app/maainfo) were carefully inspected prior to field studies. Areas of contrasted color and texture presumed to be different substrate classes or variations in SAV coverage were determined as field stations from the areal images. These field stations were visited during the benthic field sampling campaign that took place from 30 May to 3 June 2016. Global positioning system (GPS) coordinates were recorded at each station visited. Bathymetry data were acquired with the research vessel's echo sounder. The vessel had sonar on board and the sonar reading was written down at each sampling station. Benthic information was collected using a remote underwater video device [44]; collected videos were later analyzed by highly experienced experts. At each station, the cover of sediments and \%SAV species was estimated. 


\subsection{Water Column Correction (WCC)}

To obtain reflectance values, which solely represent variations in SAV abundance and not in water column properties nor in water depth, the WCC procedure was applied to the CASI sea surface reflectance image. In the current study, two WCC methods were used that retrieve bottom reflectance and require limited numbers of in situ water column optical measurements. The first model was proposed by Maritorena [32], who parameterized the model with the diffuse downwelling attenuation coefficient $\left(K_{d}, \mathrm{~m}^{-1}\right)$ to characterize the water column. The second model was proposed by Lee [33], who considered that the attenuation coefficients for the upward and downward directions are not equal and suggested using a model where the diffuse attenuation coefficients are parameterized as a function of $a$ and $b_{b}$ [26]. Bathymetry data are required by both methods. In this study, the site-specific band-ratio algorithm for bathymetry retrieval was developed using the method proposed by [45].

\subsubsection{Maritorena WCC Model}

Reference [32] proposed a model where reflectance just below the water surface $R_{w}\left(0^{-}\right)$is approximated by the following equation:

$$
R_{w}\left(0^{-}\right)=R_{\infty}+\left(R_{b}-R_{\infty}\right) \exp \left(-2 K_{d} z\right),
$$

where $R_{w}$ is the reflectance of infinitely deep water just below the water surface, $R_{b}$ is the bottom reflectance, $K_{d}$ is the diffuse downwelling attenuation coefficient of the water column and $z$ is the bottom depth. All parameters, except $z$, in this model are wavelength dependent. The model was inverted in order to derive $R_{b}$ for all image pixels:

$$
R_{b}=\frac{R_{w}-R_{\infty}}{\exp \left(-2 K_{d} z\right)}+R_{\infty}
$$

The Maritorena model was developed for reflectance just below the water surface. CASI above-water-surface reflectance was converted to the below-water-surface reflectance using the approximation of $R_{w}\left(0^{-}\right)=R_{w}\left(0^{+}\right) / t$, with $t=0.54$ [46].

The optically deep water reflectance $\left(R_{w}\right)$ was obtained as a mean reflectance of selected CASI pixels from the deep water area. $K_{d}$ was calculated from the underwater $E_{d}$ profiles according to [47]:

$$
K_{d}=-\frac{1}{\Delta z} \ln \left(\frac{E_{d}\left(z_{2}\right)}{E_{d}\left(z_{1}\right)}\right)
$$

where $\Delta z$ is the difference in measurement depths, $E_{d}\left(z_{1}\right)$ is the downwelling spectral irradiance at depth $z_{1}$ and $E_{d}\left(z_{2}\right)$ is the downwelling spectral irradiance at depth $z_{2}$, where $z_{1}$ is a reference depth closer to the water surface. $K_{d}$ was calculated for every $0.5 \mathrm{~m}$ and averaged over the entire profile.

\subsubsection{Lee WCC Model}

The second model was proposed by [33] and referred to by [34,37]. The model was developed for the water-surface remote sensing reflectance $\left(R_{r s}\right)$ :

$$
R_{r s}=0.05 \frac{b_{b}}{a+b_{b}}\left\{1-\exp \left(-3.2\left(a+b_{b}\right) z\right)\right\}+0.17 R_{b}\left\{\exp \left(-c\left(a+b_{b}\right) z\right)\right\}
$$

where $R_{b}$ is the bottom reflectance, $b_{b}$ is the total backscattering coefficient of the water column, $a$ is the total absorption coefficient of the water column and $z$ is the water depth. The model can be inverted to derive $R_{b}$ by the following equation:

$$
R_{b}=\frac{R_{r s}-0.05 \frac{b_{b}}{a+b_{b}}\left\{1-\exp \left(-3.2\left(a+b_{b}\right) z\right\}\right.}{0.17\left\{\exp \left(-c\left(a+b_{b}\right) z\right)\right\}}
$$


Constant $c$ is an adjusted factor implying to times of exponential decay [37]. Various $c$ values (ranging from 1 to 2.7) can be found from the literature [33,34,37]. Two different $c$ values ( 1 and 2) were tested in the current study, referred to as the Lee I and Lee II models, respectively. CASI FLAASH-corrected surface reflectance $R$ was converted to remote sensing reflectance $R_{r s}$ by adjusting the $Q$ factor according to $R_{r s}=R / Q$, with $Q=\pi$. Variable $a$ was measured in situ by the ACS instrument and the $b_{b}$ spectrum was calculated using following power function [48]:

$$
b_{b}(\lambda)=b_{b}(660)\left(\frac{660}{\lambda}\right)^{\eta}
$$

where $b_{b}(660)$ was measured in situ by the ECO-VSF3 and $\eta$ is dimensionless spectral slope taken equal to 0.5 for the Case-2 water type, as referred to by [37].

\subsubsection{Lee WCC Model Sensitivity Analysis}

To assess the model sensitivity to input parameters in optically complex coastal water, a simple modeling exercise was undertaken. First, the Lee algorithm was used to simulate water surface spectra (Equation (4)) using in situ measured sand bottom reflectance spectra from our spectral library [49], a predefined water depth $(2 \mathrm{~m})$, and $a$ and $b_{b}$ coefficients calculated according to $[49,50]$. Concentrations of optically active substances for $a$ and $b_{b}$ calculations were defined accordingly: $C_{\mathrm{Chl}}=2 \mathrm{mg} / \mathrm{m}^{3}$, $\mathrm{C}_{\mathrm{TSM}}=2 \mathrm{~g} / \mathrm{m}^{3}, \mathrm{a}_{\mathrm{CDOM}}=1.5 \mathrm{~m}^{-1}$, which are typical to open Baltic Sea waters [50]. The constant $c$ value was taken equal to 2 .

Calculated surface spectra were then used in the inverse model (Equation (5)) to retrieve the bottom reflectance. However, each input parameter (depth, $\mathrm{C}_{\mathrm{Chl}}, \mathrm{C}_{\mathrm{TSM}}, \mathrm{a}_{\mathrm{CDOM}}$ ) in the inverse model was changed in the predefined ranges in order to assess the model sensitivity to each parameter. The water depth values varied in the range of $2 \pm 0.5 \mathrm{~m}$. This range was defined based on the validation results of [51], where a root mean square error (RMSE) close to $0.5 \mathrm{~m}$ was achieved between the measured and modeled water depths in the Baltic Sea waters. Chl-a concentrations were changed in the ranges of $2 \pm 0.5 \mathrm{mg} / \mathrm{m}^{3}$, TSM concentration in the ranges of $2 \pm 1.5 \mathrm{~g} / \mathrm{m}^{3}$ and $\mathrm{a}_{\mathrm{CDOM}}$ in the ranges of $1.5 \pm 0.5 \mathrm{~m}^{-1}$. These ranges were defined considering the variability in concentrations of optically active substances measured at the Pakri field stations (Table 1).

\subsection{SAV Percent Cover Assessment}

To represent SAV abundance, \%SAV was chosen as a metric because \%SAV assessments were available from the study area. The linear regression method was applied to the water surface reflectance, as well as to retrieve bottom reflectance to establish an empirical relationship between in situ estimated $\%$ SAV and the corresponding $3 \times 3$ pixel reflectance value extracted from the CASI image.

In total, 181 stations were visited during the field sampling campaign. Of these, 151 field stations remained in the depth range of 0-3 $\mathrm{m}$ and data from these stations were included to the analysis of community level \%SAV estimation. The maximum depth of \%SAV assessment was delineated by $3 \mathrm{~m}$ because our previous studies showed that the detectable depth limit for most SAV species in our coastal waters is near $3 \mathrm{~m}$, due to water column optical properties [52]. The range of \%SAV samples was $0-100 \%$ with a mean value of $52 \%$. Prevalent macrophyte species in the study area were higher plants (Stuckenia pectinata, Zannichellia palustris, Zostera marina, Ruppia maritima), brown macroalgae (Fucus vesiculosus, Pilayella littoralis), green macroalgae (Cladophora glomerata), red macroalgae (Ceramium tenuicorne) and different carophyte communities.

In addition to the community level \%SAV assessment, we also addressed the issue of species and/or class level \%SAV mapping. Previous studies from the Baltic Sea showed that species level habitat maps cannot be retrieved from the Baltic Sea by remote sensing methods [8,53]. The reason for it is the high spatial heterogeneity, as well as the high spectral similarity between different species belonging to the same vegetation class (brown macroalgae, red macroalgae, green macroalgae, higher plants, etc.). Therefore, a class level assessment was used instead of a species level assessment. A wide 
range of \%SAV is needed to establish an accurate relationship between the parameters and the spectral response [54]. We had the most representative number of samples from the higher plants class (73 samples from the \%SAV range of 0-100\%) and this class was used for the class level \%SAV assessment. Samples where higher plants were mixed with macroalgae were removed from the analysis.

\section{Results}

\subsection{Water Column Optical Properties}

Table 1 shows the results of field measurements of optically active water column constituents at the field stations visited (Figure 1). Measured concentrations are characteristic to complex Case-2 coastal waters. Variables $K_{d}, a$ and $b_{b}$ for each measurement station are presented in Figure 2 . High $K_{d}$ values in both shorter (blue bands) and longer (red bands) wavelengths indicate the high rate of light attenuation at those spectral regions. The high absorption in the longer wavelengths is attributable to water molecules. Colored dissolved organic matter (CDOM) contributes highly to the absorption in the shorter wavelengths in optically complex waters. Chlorophyll contributes additionally to the absorption in shorter and longer wavelengths. While the blue spectral region has the best light penetration ability in optically clear waters, then less clear Case- 2 waters allow the deepest light penetration in the green spectral region, as also seen in Figure 2a,b.

Calculated $b_{b}$ spectra show a slight increase towards shorter wavelengths (Figure 2c). Both shape and magnitude of $b_{b}$ spectra can vary dramatically in different parts of the Baltic Sea (open Baltic Sea, turbid estuaries, etc.) as evidenced by the in situ measurements provided in [55]. Our calculated $b_{b}$ spectral shapes and magnitudes showed good agreement with the measurement results of [55], which were acquired from the moderately turbid Baltic Sea waters with similar total suspended matter (TSM) concentrations.

The highest concentrations of optically active constituents, as well as the highest $K_{d}, a$ and $b_{b}$ values, were measured at station 1 (Table 1, Figure 2). This station was located nearest to the mainland and not far from the Kurkse harbor (Figure 1), and therefore influenced the most by the terrestrial runoff. The harbor entrance was dredged at the time of the data collection, which might have had an additional influence on the water quality in the area. Higher $b_{b}$ values at station 1 (Figure 2c) are characteristic to the higher sediment loads. The lowest CDOM and TSM concentrations, as well as the lowest $K_{d}$ values, were measured at station 4 (Table 1, Figure 2a). This station was farthest offshore (Figure 1) and expected to have the clearest water conditions. Unfortunately, an optical package containing the ACS and ECO-VSF3 instruments failed to work at station 4. Concentrations of water column constituents at stations 2 and 3 were relatively similar, exhibiting the highest difference in chlorophyll concentration (Table 1).

Table 1. Concentrations of optically active water color constituents for the Pakri field sites: colored dissolved organic matter $\left(\mathrm{aCDOM}, \mathrm{m}^{-1}\right)$, total suspended matter $\left(\mathrm{TSM}, \mathrm{g} \mathrm{m}^{-3}\right)$ and chlorophyll a (Chl-a, $\left.\mathrm{mg} \mathrm{m}^{-3}\right)$.

\begin{tabular}{ccccc}
\hline & St01 & St02 & St03 & St04 \\
\hline Depth, m & 3.5 & 7.0 & 3.5 & 6.5 \\
a $_{\text {CDOM }}(440), \mathrm{m}^{-1}$ & 0.63 & 0.58 & 0.64 & 0.52 \\
TSM, g m & \\
${\text { Chl-a, } \mathrm{mg} \mathrm{m}^{-3}}^{-3}$ & 9.00 & 6.93 & 7.27 & 5.70 \\
\hline
\end{tabular}

In general, the water column properties can be considered relatively constant for the field stations visited (Table 1). It was decided to use the measured water optical properties from station 2 as input data for the WCC models instead of using an average of all stations. Station 1 was neglected, as the water quality was affected by the dredging activity. Measurements from station 4 could not be used, as a part of the water optics data were missing. The water column optical data from stations 2 and 
3 showed only minor differences (Figure 2). The fact that ground measurements at station 2 were performed exactly at the time of the overflight was in favor of choosing the data from that station for the WCC model parameterization.
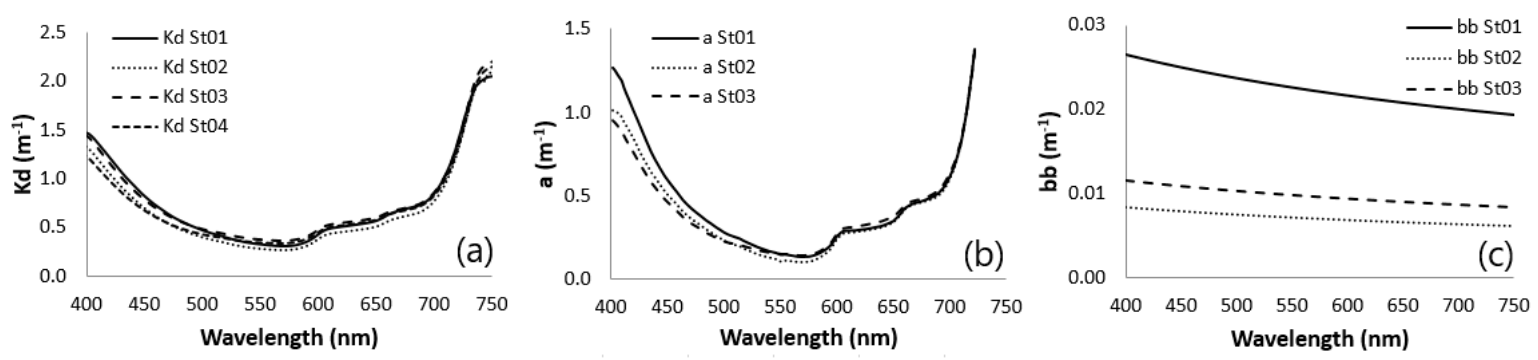

Figure 2. Overview of water optical properties at the field stations: (a) diffuse attenuation coefficient, $K_{d} ;(\mathbf{b})$ total absorption coefficient, $a$; (c) total backscattering coefficient, $b_{b}$.

\subsection{Bathymetry Model}

A bathymetry map was generated from regression analysis between field data and band ratio following the method proposed by [45]. The log-transformed surface reflectance ratio of two CASI bands was regressed against in situ measured water depth data to derive a prediction for bathymetry (Figure 3):

$$
\begin{gathered}
z=58.567 x-57.23 \\
x=\frac{\ln (1000 * R(\text { green } ; 520 \mathrm{~nm})}{\ln (1000 * R(\text { yellow } ; 608 \mathrm{~nm})}
\end{gathered}
$$

The green and yellow spectral regions were used for the bathymetry estimation, as those regions are shown to provide the highest level of depth information in complex coastal waters [51].

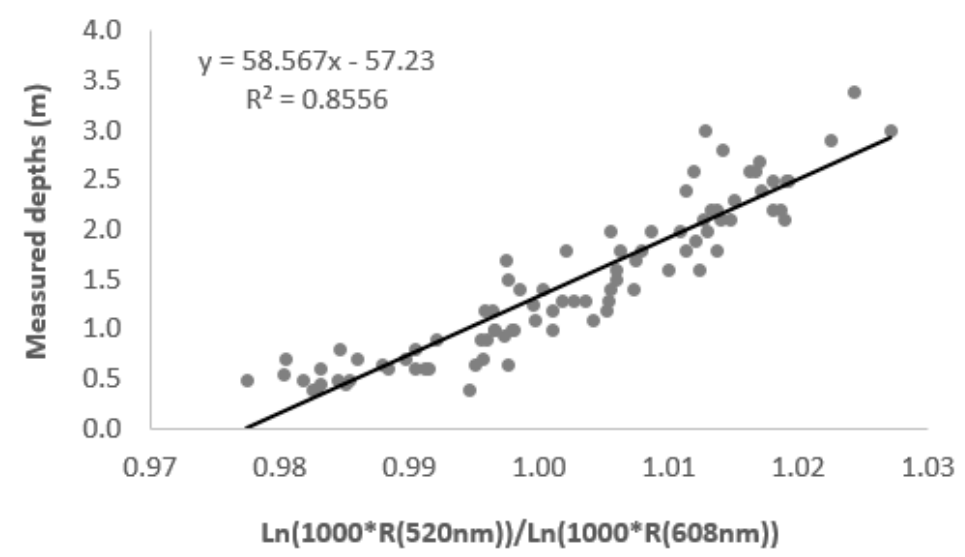

Figure 3. Relationship between in situ measured water depth and the ratio of green to yellow CASI water surface reflectance.

\subsection{Retrieval of Bottom Reflectance}

WCC was applied to the CASI water surface reflectance image using the Maritorena model (Equation (2)) and the Lee model with different $c$ values (Equation (5)). Figures 4 and 5 show water surface spectra and results of the Maritorena, Lee I and Lee II models, respectively. In Figure 4, reflectance of the sand substrate from various water depths are extracted from the uncorrected image, as well as from images corrected with the referred WCC models. Uncorrected water surface spectra show a general trend of decreasing spectral magnitudes with increasing water depth (Figure 4a). Corrected spectra of the same bottom type are expected to have similar spectral shapes, as well as 
similar absolute values irrespective of the water depth. However, our results show that this goal is not easy to achieve in the complex Baltic Sea waters.

Sand reflectance spectral shape is generally characterized by increased reflectance towards longer wavelengths without exhibiting any remarkable absorption features. However, the spectral shapes retrieved by using both the Maritorena and Lee WCC models exhibit a chlorophyll a absorption feature near $675 \mathrm{~nm}$. This may be explained either by the presence of microalgae within the sand or by the inaccurate WCC. The Maritorena model retrieved sand spectra that show rather large variations in absolute values (Figure 4b). Retrieved spectral values increase with increasing water depth displaying an unsuccessful water column correction.

The Lee I model provided lower variations in spectral magnitudes compared to the uncorrected spectra (Figure 4c). However, the model failed to retrieve the bottom reflectance before $500 \mathrm{~nm}$ at depths over $2 \mathrm{~m}$, where corrected spectra present an abrupt peak. It means that for some extent the Lee I model succeeded to reduce the variation of the reflectance conditioned on the water depth differences. Results of the Lee II model (Figure $4 \mathrm{~d}$ ) present bottom reflectance, which becomes more and more skewed with the increasing water depth. The model overestimated bottom reflectance, especially before $550 \mathrm{~nm}$ and after $600 \mathrm{~nm}$. Reasonable absolute values were retrieved only in a rather narrow wavelength region ranging from 550 to $600 \mathrm{~nm}$.

Figure 5 shows dense SAV (\%SAV > 80\%) reflectance spectra at various water depths before and after water column correction. Generally, the same results were achieved as in the case of sand substrate. Dense SAV water surface spectra do not show a clear decrease in absolute values with increasing water depth (Figure 5a). The Maritorena model seemed to preserve the spectral shapes, but overestimated the magnitudes of substrate spectra at greater depths (Figure 5b). The Lee models overestimated the magnitudes of retrieved substrate spectra in shorter and longer wavelengths. The application of the Lee II model resulted in significantly higher overestimation (abrupt peaks in shorter and longer wavelengths) compared to the Lee I model (Figure 5d).
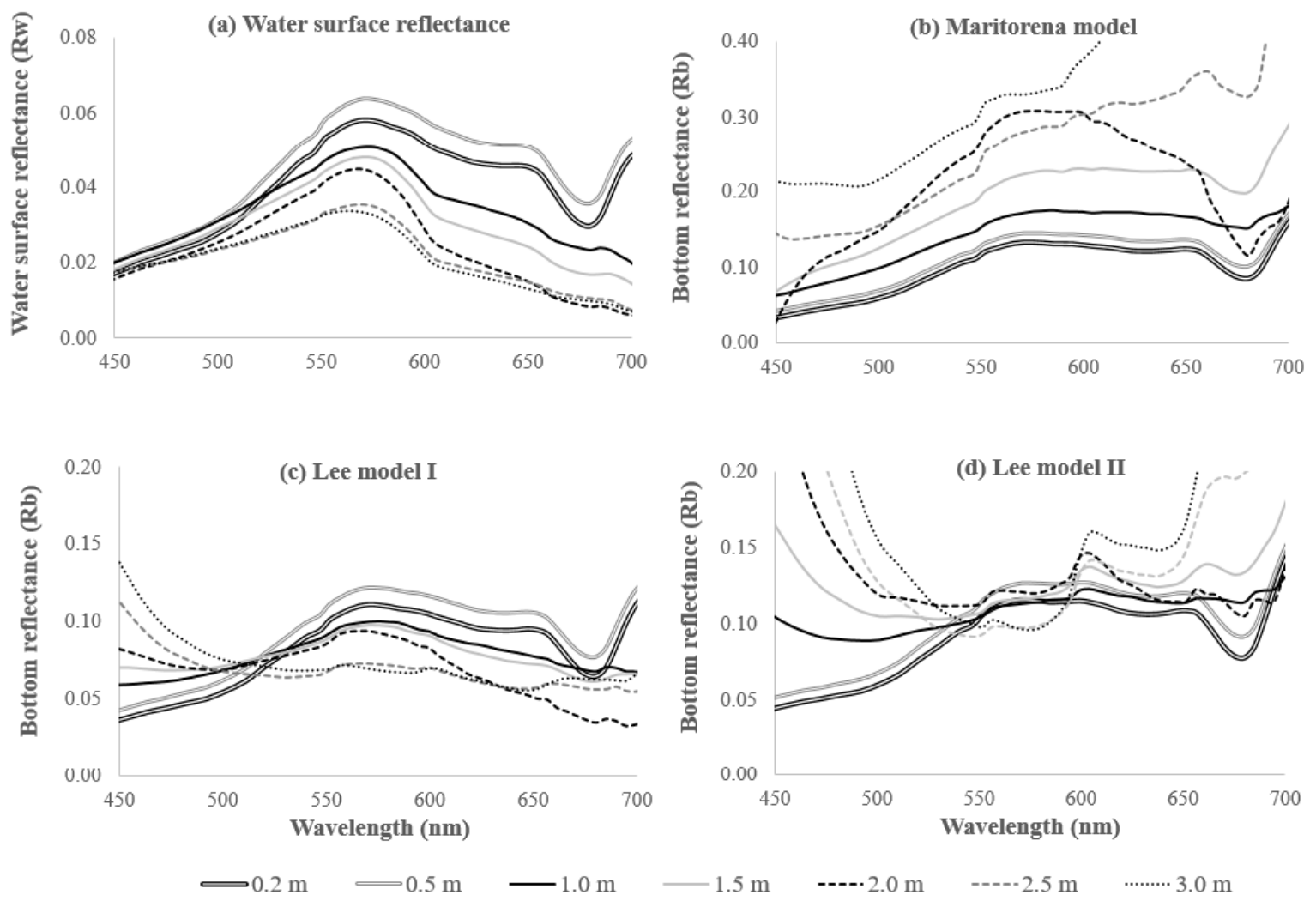

Figure 4. Sand reflectance spectra at various water depths before and after water column correction. 

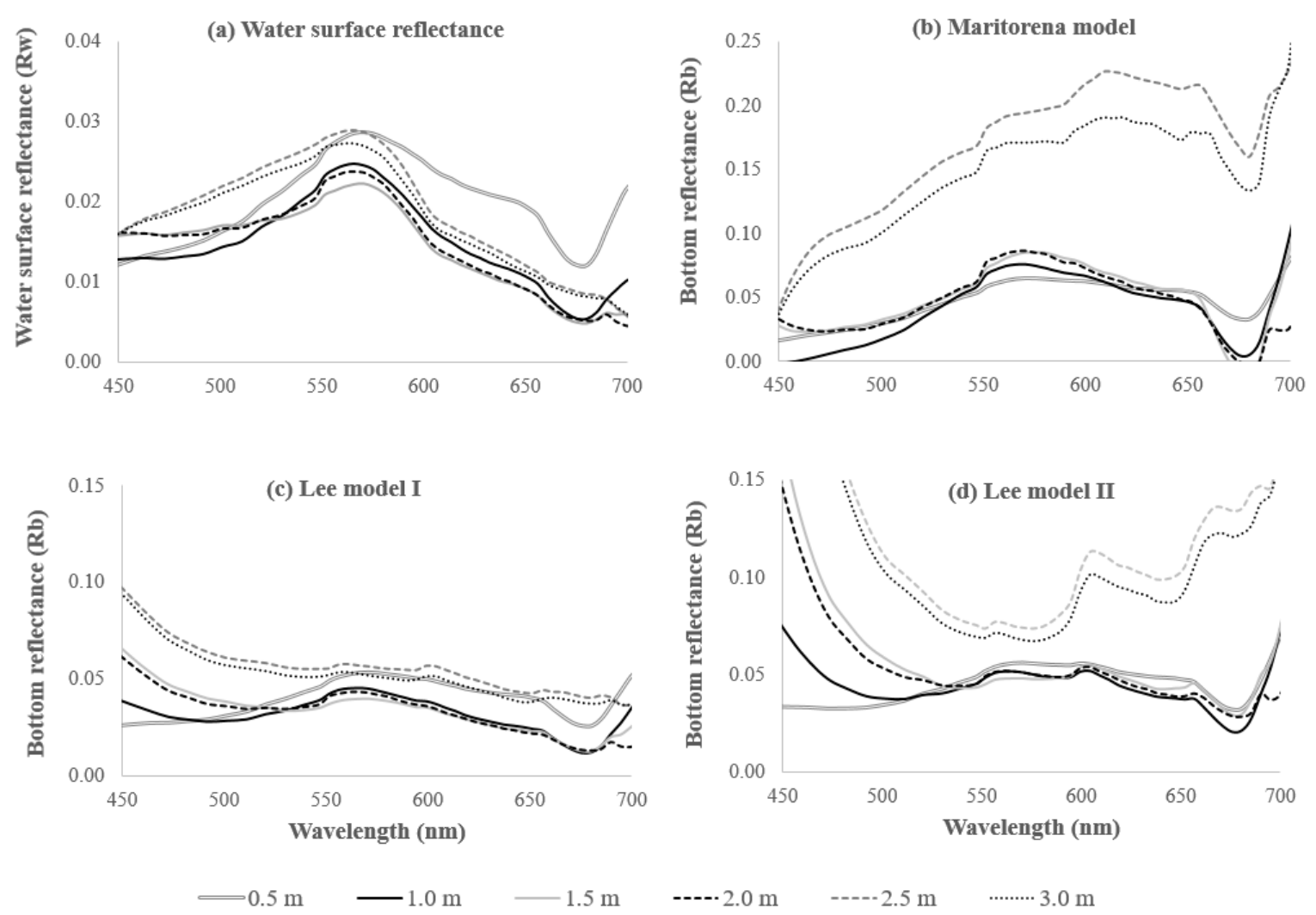

Figure 5. Dense vegetation ( $\% \mathrm{SAV}>80 \%$ ) reflectance spectra at various water depths before and after water column correction.

\subsection{Model Sensitivity to Input Parameters}

Unrealistic bottom spectral shapes retrieved by the Lee II model necessitated assessment of the model sensitivity to input parameters, such as water depth, Chl-a, CDOM and TSM concentrations. Figure 6 shows the results of sand substrate retrieval if a single input parameter differs slightly from the correct value. Our results show that incorrect TSM concentration in model parameterization affects significantly both shorter and longer wavelengths (Figure 6a). TSM underestimation by only $0.5 \mathrm{~g} / \mathrm{m}^{3}$ results in abrupt peaks before $450 \mathrm{~nm}$ and after $680 \mathrm{~nm}$. The model seems to be the least sensitive to Chl-a variations, as only the spectral region above $700 \mathrm{~nm}$ is affected by it (Figure 6b). Variations in CDOM concentration affect mainly shorter wavelengths (Figure 6c). Overestimation of water depth by $0.5 \mathrm{~m}$ in model parameterization (Figure $6 \mathrm{~d}$ ) results in the most skewed shapes of bottom reflectance, where most of the spectral region is affected.

The results of model sensitivity analyses show that small inaccuracies in model parameterization can result in unrealistic bottom spectra in the complex Case-2 waters. Moreover, the combination of several incorrect parameters may affect the retrieval of bottom spectra even to a larger extent. 

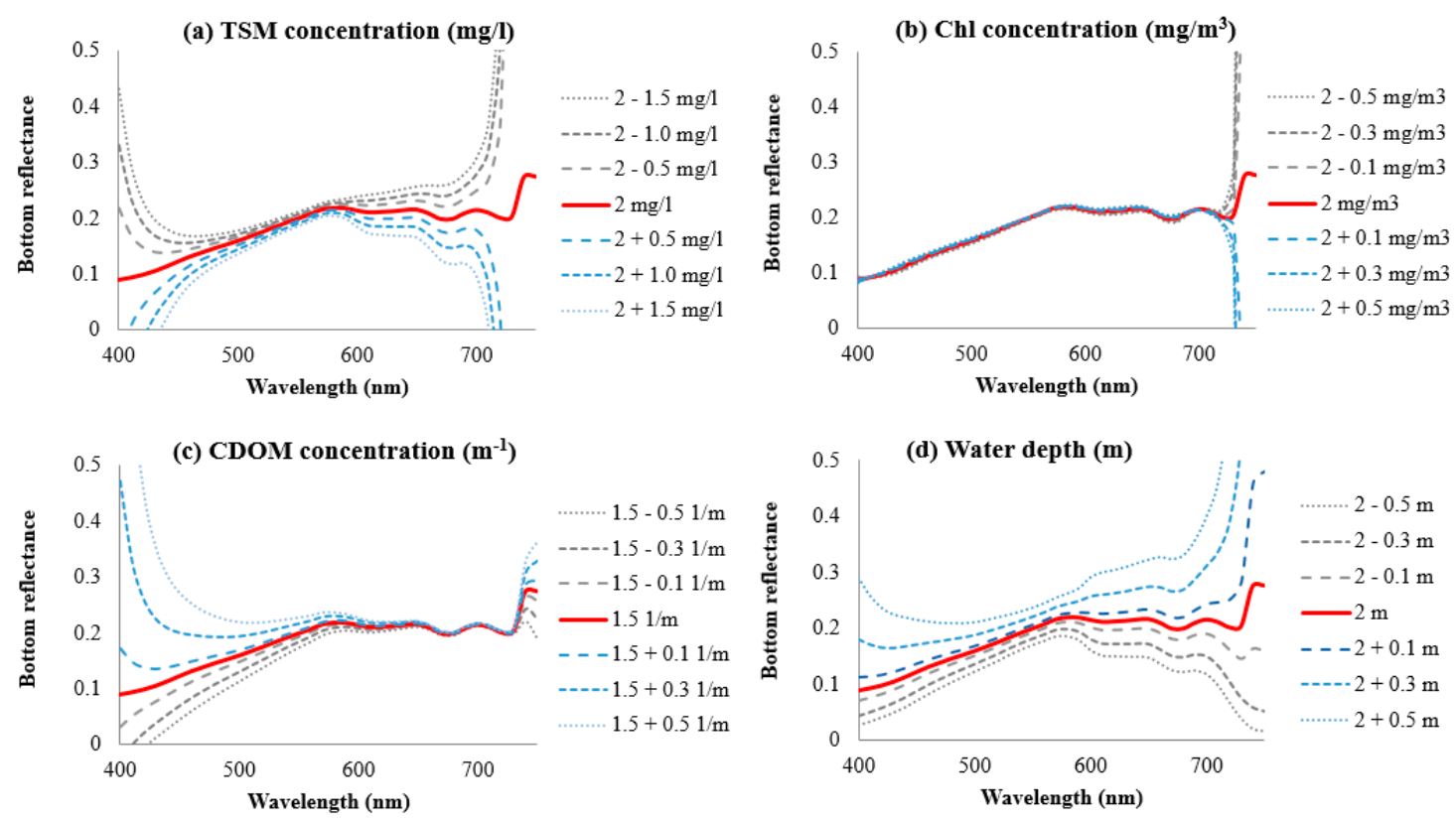

Figure 6. Lee model's sensitivity to input parameters in retrieving sand substrate from water surface reflectance. Correct model input parameters include $\mathrm{C}_{\mathrm{Chl}}=2 \mathrm{mg} / \mathrm{m}^{3}, \mathrm{C}_{\mathrm{TSM}}=2 \mathrm{~g} / \mathrm{m}^{3}$ and $\mathrm{a}_{\mathrm{CDOM}}$ $=1.5 \mathrm{~m}^{-1}$, depth $=2 \mathrm{~m}$. Retrieved substrate spectra are affected by (a) total suspended matter concentration (TSM) variations, (b) chlorophyll-a (Chl) concentration variations, (c) colored dissolved organic matter $(\mathrm{CDOM})$ concentration variations and $(\mathbf{d})$ water depth variations.

\subsection{Correlation Analysis of CASI Reflectance with \%SAV}

The spectral region between 550 and $600 \mathrm{~nm}$ was used in our subsequent analysis for SAV abundance quantification as this spectral region was the least sensitive to input parameter variations. Our aim was to evaluate the performance of WCC on improving the relationship between \%SAV and bottom reflectance, as well as to define at which depth WCC starts to give positive impact on the assessment of \%SAV.

The results revealed that the optimal band having the strongest correlation with the community level \%SAV was a band centered at $551.5 \mathrm{~nm}$. Table 2 compares the strength of relationships between the reflectance at the $551.5 \mathrm{~nm}$ and community level \%SAV in terms of the coefficient of determination $\left(R^{2}\right)$ and root mean square error (RMSE) for the water surface reflectance and bottom reflectance images. The analysis was done separately for three depth ranges: $0-1,0-2$ and $0-3 \mathrm{~m}$. As expected, the highest correlations were found for the shallowest depth range $(0-1 \mathrm{~m})$. Correlations became gradually weaker as the depth range was expanded first to $0-2 \mathrm{~m}$ and then to $0-3 \mathrm{~m}$.

Table 2. The coefficients of determination $\left(R^{2}\right)$ and root mean square error (RMSE) between the reflectance at the $551.5 \mathrm{~nm}$ and community level submerged aquatic vegetation percent cover for the water surface reflectance and bottom reflectance produced by the Maritorena and Lee water column correction models.

\begin{tabular}{cccccccccc}
\hline \multirow{2}{*}{$\begin{array}{c}\text { Depth } \\
\text { Range }\end{array}$} & $\begin{array}{c}\text { In Situ Field } \\
\text { Stations }\end{array}$ & \multicolumn{2}{c}{ Surface Reflectance } & \multicolumn{2}{c}{ Maritorena Model } & \multicolumn{2}{c}{ Lee I Model } & \multicolumn{2}{c}{ Lee II Model } \\
\cline { 3 - 10 } & & $\mathbf{R}^{\mathbf{2}}$ & RMSE & $\mathbf{R}^{\mathbf{2}}$ & $\mathbf{R M S E}$ & $\mathbf{R}^{\mathbf{2}}$ & RMSE & $\mathbf{R}^{\mathbf{2}}$ & RMSE \\
\hline $0-1 \mathrm{~m}$ & 60 & 0.69 & 0.192 & 0.55 & 0.230 & 0.68 & 0.194 & 0.66 & 0.199 \\
$0-2 \mathrm{~m}$ & $115(+55)$ & 0.58 & 0.211 & 0.42 & 0.247 & 0.59 & 0.208 & 0.60 & 0.206 \\
$0-3 \mathrm{~m}$ & $151(+36)$ & 0.49 & 0.231 & 0.30 & 0.270 & 0.52 & 0.224 & 0.56 & 0.213 \\
\hline
\end{tabular}

Although the surface reflectance image showed the highest $R^{2}$ for the shallowest depth range $\left(R^{2}=0.69\right)$, it also showed the greatest decrease with increasing water depth (Table 2$)$. It means that while $69 \%$ of the variability in the \%SAV could be explained by the CASI surface reflectance image in 
the depth range of $0-1 \mathrm{~m}$, only approximately $58 \%$ of the variability could be explained in the depth range of 0-2 $\mathrm{m}$ and $49 \%$ in the depth range of $0-3 \mathrm{~m}$. Such $\mathrm{R}^{2}$ reduction clearly illustrates the need for the WCC.

The application of the Maritorena WCC model did not improve the relationship between image reflectance and \%SAV (Table 2). On the contrary, it reduced the correlation significantly. This can be explained by the fact that in the current study the magnitude of reflectance spectra was used as an indicator of the SAV abundance. However, as seen from Figures 4 and 5, the Maritorena model failed to retrieve correct magnitudes of bottom spectra. At the same time, the application of the Lee WCC models generally improved the relations between spectral response and \%SAV (Table 2). Only the shallowest depth range $(0-1 \mathrm{~m})$ showed lower $\mathrm{R}^{2}$ and higher RMSE values than surface reflectance. WCC started to give slightly positive impact if the intermediate depth range $(0-2 \mathrm{~m})$ was included to the analysis. The improvement was even higher if the greatest depths $(0-3 \mathrm{~m})$ were included. The Lee II model showed the highest $R^{2}$ and lowest RMSE in the 0-2 $\mathrm{m}$ depth range $\left(R^{2}=0.60\right.$; RMSE $\left.=0.206\right)$, as well as in the $0-3 \mathrm{~m}$ depth range $\left(\mathrm{R}^{2}=0.56\right.$; RMSE $\left.=0.213\right)$. The analysis of retrieved bottom spectra (Figures 4 and 5), as well as the decrease of correlation with increasing water depth (Table 2) shows that the WCC models were not entirely successful in our waters. However, although the quality of WCC was not considered high, it still provided better results in \%SAV assessment than not performing any correction.

In addition to the community level \%SAV assessment, we also performed class level \%SAV assessment with the higher plants class. The results revealed that the optimal band having the strongest correlation with the higher plants \%SAV was a band centered at $570.6 \mathrm{~nm}$. Table 3 compares the strengths of relationships between the spectral response and the higher plants $\% S A V$. The $R^{2}$ values at class level are to some extent higher than at community level. At the same time, RMSE values are also generally higher, except in the $0-2 \mathrm{~m}$ depth range. Again, the Lee II model provided the highest correlations at the greatest depth range (Table 3). Figure 7 presents relationships between the reflectance and higher plants \%SAV at the depth range of 0-3 m displaying the correlations for the water surface reflectance and bottom reflectance.
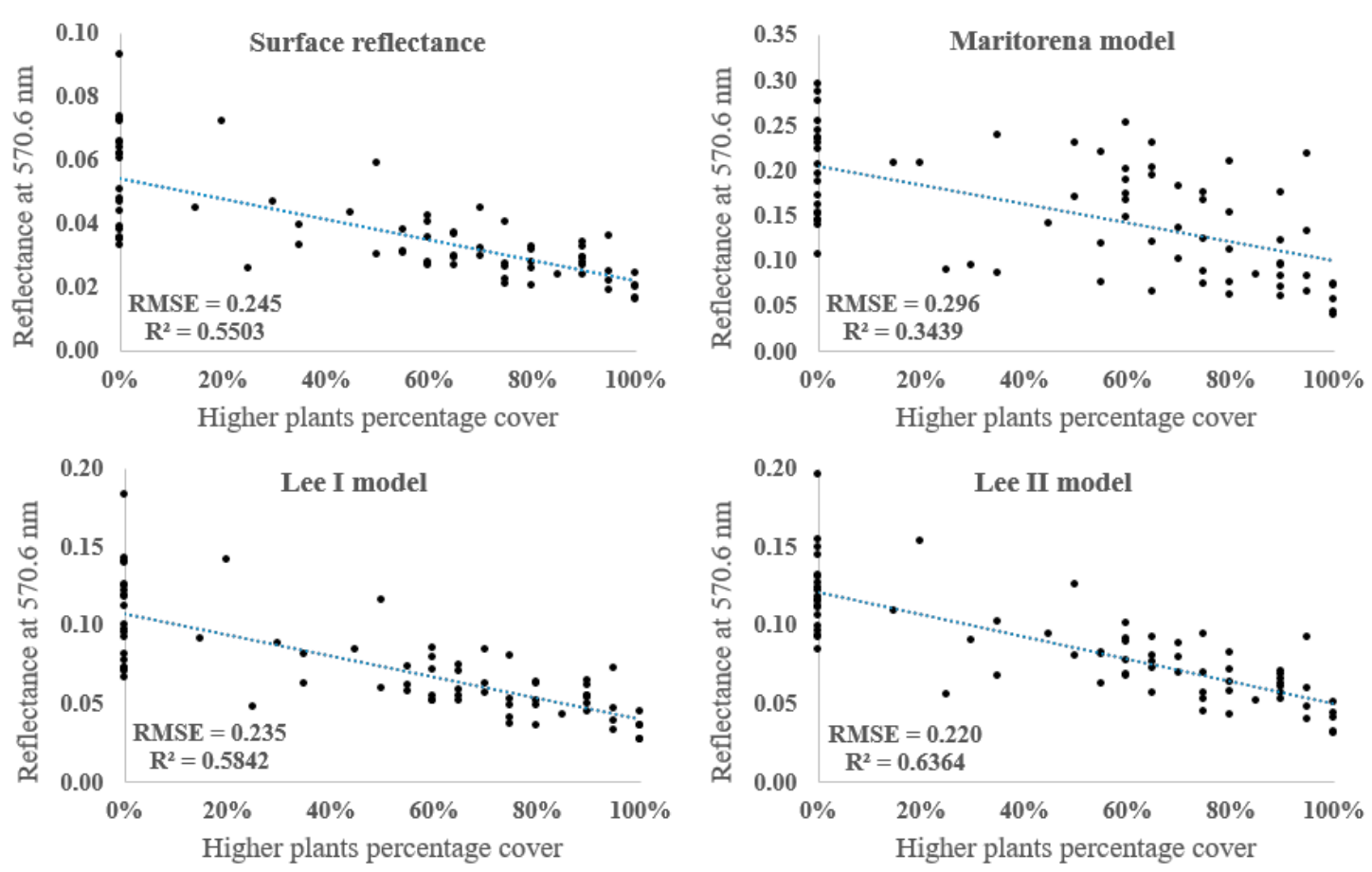

Figure 7. Relationships between the reflectance at the $570.6 \mathrm{~nm}$ and higher plants percent cover at the depth range of $0-3 \mathrm{~m}$ for the water surface reflectance and bottom reflectance produced by the Maritorena, Lee I and Lee II water column correction models. 
Table 3. The coefficients of determination $\left(R^{2}\right)$ and root mean square error (RMSE) between the reflectance at the $570.6 \mathrm{~nm}$ and higher plants percent cover for the water surface reflectance and bottom reflectance produced by the Maritorena and Lee water column correction models.

\begin{tabular}{cccccccccc}
\hline \multirow{2}{*}{$\begin{array}{c}\text { Depth } \\
\text { Range }\end{array}$} & $\begin{array}{c}\text { In Situ Field } \\
\text { Stations }\end{array}$ & \multicolumn{2}{c}{ Surface Reflectance } & \multicolumn{2}{c}{ Maritorena Model } & \multicolumn{2}{c}{ Lee I Model } & \multicolumn{2}{c}{ Lee II Model } \\
\cline { 3 - 9 } & & $\mathbf{R}^{\mathbf{2}}$ & RMSE & $\mathbf{R}^{\mathbf{2}}$ & RMSE & $\mathbf{R}^{\mathbf{2}}$ & RMSE & $\mathbf{R}^{\mathbf{2}}$ & RMSE \\
\hline $0-1 \mathrm{~m}$ & 25 & 0.75 & 0.196 & 0.56 & 0.258 & 0.74 & 0.199 & 0.71 & 0.210 \\
$0-2 \mathrm{~m}$ & $51(+26)$ & 0.70 & 0.206 & 0.49 & 0.267 & 0.71 & 0.202 & 0.71 & 0.199 \\
$0-3 \mathrm{~m}$ & $73(+22)$ & 0.55 & 0.245 & 0.34 & 0.296 & 0.58 & 0.235 & 0.64 & 0.220 \\
\hline
\end{tabular}

\section{Discussion}

In this study, the Maritorena and Lee WCC models were tested in Baltic Sea Case-2 waters. These models require water optics measurement data, such as $K_{d}, a$ and $b_{b}$, as well as water depth estimates. While model parameterization data were collected during the field campaign, we did not manage to collect the bottom reflectance spectra needed for the validation of the WCC results. Therefore, the WCC performance was assessed similarly to [35], whose hypothesis was, that if the WCC was accurately performed, then the depth factor on the bottom reflectance would be eliminated and the bottom albedo for a particular bottom types at various depths would be similar. Moreover, we have collected a spectral library of Baltic Sea bottom types and vegetation species during our previous field studies $[49,50,56]$; thus it is easy to see from the retrieved bottom reflectance spectra if it resembles something that exists in nature.

Our results showed that bottom spectra retrieved by the Maritorena model from various water depths showed rather large variations in absolute values. Similar results were achieved by [26,52], who showed that the Maritorena WCC model failed to retrieve correct reflectance magnitudes, but at the same time succeeded in retrieving the spectral shapes for substrates. Therefore, it can be assumed that the Maritorena model may be successful in benthic habitat classification procedures, such as the spectral angle mapper (SAM), which classifies spectra in terms of the spectral shape and not in absolute reflectance magnitude. For example, [36] applied two different classification algorithms to the bottom spectra corrected by the Maritorena WCC model. They concluded that the SAM classification algorithm outperformed the algorithm that classifies spectra in terms of absolute values. However, the performance of the Maritorena model for SAV classification was not evaluated in the context of the current study.

The Lee models were more successful in retrieving the correct absolute values, as the bottom spectra from various water depths showed lower variation in absolute values after WCC. However, it is important to note that the Lee models were only effective at certain spectral ranges. At greater depths, the Lee I model overestimated retrieved substrate spectral magnitudes in shorter wavelengths and the Lee II model in both shorter and longer wavelengths. The overcorrection of bottom spectra increased as a higher $c$ value (Lee II model) was used for the model parameterization. Similarly, the width of the spectral range, were Lee models provided reasonable spectral values, decreased with increasing $c$ value.

While water column correction is successfully applied in clear ocean waters, its application is questionable in less clear Case-2 waters. In principle, the WCC can be effective also in complex waters, but it requires accurate parameterization at each point in the study site. The WCC methods used assume uniform water optical properties over the area of interest. Results of in situ measurements indicated that measured concentrations over the visited sites were relatively constant. However, the model sensitivity analyses showed that this variability is high enough to affect retrieval of accurate bottom spectra.

In addition, accurate water depth data are generally not known through the study area. In the current study, a site-specific band-ratio algorithm was developed for the bathymetry retrieval. Our previous validation results showed that a RMSE between 0.3 and $0.5 \mathrm{~m}$ was achieved between in situ and modeled bathymetry data from the Baltic Sea waters [51]. The current WCC model sensitivity 
analysis showed that overestimation of water depth by $0.5 \mathrm{~m}$ results in unrealistic bottom spectra. These results confirm once again that WCC is more challenging to apply in less clear waters, as it requires more accurate parameterization compared to the clear water environment.

Several researchers found that the implementation of WCC improved the accuracy of benthic substrate classification maps $[29,36,57]$. WCC should also facilitate the quantification of SAV abundance, but there are very few comparative studies regarding the evaluation of the given improvement. For example, [21] found that WCC proved useful for improving the regression between image reflectance and SAV LAI. At the same time, [58] estimated macroalgae biomass in very clear Tahitian waters where WCC was attempted, but results were found not to be significant, as the depth range covered only $0-3 \mathrm{~m}$.

In the current study, the spectral region between 550 and $600 \mathrm{~nm}$ was used for the $\% \mathrm{SAV}$ assessment as this spectral region was the least overcorrected by any of the WCC models used. The results showed that while in the shallowest depth range $(0-1 \mathrm{~m})$ uncorrected water surface reflectance related better with \%SAV, both in community as well as in class level, then the Lee WCC algorithm started to give positive impact if the depth range was expanded to $0-2 \mathrm{~m}$. Improvement was more significant when the depth range of 0-3 $\mathrm{m}$ was included to the assessment. The model (Lee II model) that retrieved the most skewed bottom spectral shapes resulted in the highest correlation with \%SAV. This can be explained by the fact that the spectral bands used for the correlation ( 551.5 and $570.6 \mathrm{~nm}$ for community level and class level, respectively) remained reasonably well corrected.

In this study, \%SAV was first assessed at community level, where all the SAV species present in the study area were incorporated to the analysis. Then, class level \%SAV assessment was evaluated using the higher plants class as an example. Species level abundance quantification is not considered reasonable in the Baltic Sea coastal waters due to low water transparency, mixed nature of vegetation species and high interspecies spectral similarity. Relatively good classification results were achieved in the Baltic Sea coastal waters using vegetation classes, such as "filamentous green macroalgae," "charophytes," "higher plants," "brown macroalgae" and "red macroalgae" [8,53]. That is why class level SAV abundance assessment is considered optimal in our waters. Our results showed that class level \%SAV assessment provided higher $\mathrm{R}^{2}$ values, but also higher RMSE values compared to the community level assessment. However, only one representative vegetation class was considered in the current study. More extensive research considering all of the SAV classes present in the study area should be conducted to find out whether the \%SAV assessment at class level is superior to the community level.

\section{Conclusions}

WCC models proposed by Maritorena and Lee, which require limited numbers of in situ water column optical measurements, were applied to the optically complex Baltic Sea waters to retrieve bottom reflectance spectra. Corrected spectra of the same substrate should have similar spectral shapes, as well as similar absolute values, irrespective of the water depth. The Maritorena model retrieved bottom spectra that showed rather large variations in absolute values, but at the same time succeeded in retrieving the spectral shapes for substrates. Therefore, the model is not appropriate in SAV quantification applications, which require correct spectral magnitudes. However, it may be successful in benthic habitat classification procedures, which classify spectra in terms of the spectral shape and not in absolute value.

The Lee model was more successful in retrieving spectral values than spectral shapes. Correct spectral values were retrieved in a rather narrow wavelength region ranging from 550 to $600 \mathrm{~nm}$. Shorter and longer spectral regions were significantly overcorrected, resulting in unrealistic spectral shapes. The performance of such WCC models in complex waters depends highly on the input parameters, requiring accurate parameterization at each point in the study site. Slight under- or overestimations of water depth and water column optical properties affect retrieval of correct bottom spectra, whereas shorter and longer wavelengths are the most affected. As such, the model is not 
effective in applications requiring correct spectral shapes. However, the spectral region, the least sensitive to input parameters variability (550-600 $\mathrm{nm}$ ), can be used for the SAV quantification.

Our results showed that although the quality of the Lee model was not considered high, it still provided better results in \%SAV assessment than not performing any WCC correction. The application of the Lee model started to give positive impact if the depth range was expanded to $0-2 \mathrm{~m}$, as correlations between reflectance and \%SAV increased slightly compared to the uncorrected data. However, this improvement was so modest that it was not worth performing such a time-consuming process if the water depth is restricted to $2 \mathrm{~m}$. Improvement was more significant when the depth range of 0-3 $\mathrm{m}$ was included to the assessment.

Author Contributions: Conceptualization, E.V.; Formal analysis, E.V. and B.P.; Investigation, E.V.; Methodology, E.V. and T.K.; Resources, E.V., B.P. and T.K.; Validation, E.V.; Visualization, E.V.; Writing—original draft, E.V.; Writing-review and editing, T.K. All authors have read and agreed to the published version of the manuscript.

Funding: This research was funded by the Estonian Research Council, grant numbers PUT1049 and PUT PRG302.

Acknowledgments: We are grateful to the Estonian Land Board for providing aerial photographs and to the Latvian Institute for Environmental Solutions for acquiring CASI data. We wish to thank Teemar Püss, Kaire Kaljurand and Tiia Möller for their help in collecting and analyzing field data.

Conflicts of Interest: The authors declare no conflict of interest.

\section{References}

1. Dekker, A.G.; Brando, V.E.; Anstee, J.M. Retrospective seagrass change detection in a shallow coastal tidal Australian lake. Remote Sens. Environ. 2005, 97, 415-433. [CrossRef]

2. Kutser, T.; Miller, I.; Jupp, D.L.B. Mapping coral reef benthic substrates using hyperspectral space-borne images and spectral libraries. Estuar. Coast. Shelf Sci. 2006, 70, 449-460. [CrossRef]

3. Phinn, S.; Roelfsema, C.; Dekker, A.; Brando, V.; Anstee, J. Mapping seagrass species, cover and biomass in shallow waters: An assessment of satellite multi-spectral and airborne hyper-spectral imaging systems in Moreton Bay (Australia). Remote Sens. Environ. 2008, 112, 3413-3425. [CrossRef]

4. Lyons, M.; Phinn, S.; Roelfsema, C. Integrating QuickBird multi-spectral satellite and field data: Mapping bathymetry, seagrass cover, seagrass species and change in Moreton Bay, Australia in 2004 and 2007. Remote Sens. 2011, 3, 42-64. [CrossRef]

5. Pasqualini, V.; Pergent-Martini, C.; Pergent, G.; Agreil, M.; Skoufas, G.; Sourbes, L.; Tsirika, A. Use of SPOT 5 for mapping seagrasses: An application to Posidonia oceanica. Remote Sens. Environ. 2005, 94, $39-45$. [CrossRef]

6. Fornes, A.; Basterretxea, G.; Orfila, A.; Jordi, A.; Alvarez, A.; Tintore, J. Mapping Posidonia oceanica from IKONOS. ISPRS J. Photogranmm. 2006, 60, 315-322. [CrossRef]

7. Gagnon, P.; Scheibling, R.E.; Jones, W.; Tully, D. The role of digital bathymetry in mapping shallow marine vegetation from hyperspectral image data. Int. J. Remote Sens. 2008, 29, 879-904. [CrossRef]

8. Vahtmäe, E.; Kutser, T. Classifying the Baltic Sea Shallow Water Habitats Using Image-Based and Spectral Library Methods. Remote Sens. 2013, 5, 2451-2474. [CrossRef]

9. Roelfsema, C.M.; Phinn, S.R.; Udy, N.; Maxwell, P. An Integrated Field and Remote Sensing Approach for Mapping Seagrass Cover, Moreton Bay, Australia. Spatial Sci. 2009, 54, 45-62. [CrossRef]

10. Zimmerman, R.C. A bio-optical model of irradiance distribution and photosynthesis in seagrass canopies. Limnol. Oceanogr. 2003, 48, 568-585. [CrossRef]

11. McPherson, M.L.; Hill, V.J.; Zimmerman, R.C.; Dierssen, H.M. The optical properties of Greater Florida Bay: Implications for seagrass abundance. Estuar. Coasts 2011, 34. [CrossRef]

12. Kutser, T.; Hedley, J.; Giardino, C.; Roelfsema, C.; Brando, V.E. Remote sensing of shallow waters-A 50 year retrospective and future directions. Rem. Sens Environ. 2020, 240, 111619. [CrossRef]

13. Pu, R.; Bell, S.; Meyer, C.; Baggett, L.; Zhao, Y. Mapping and assessing seagrass along the western coast of Florida using Landsat TM and EO-1 ALI/Hyperion imagery. Estuar. Coas. Shelf Sci. 2012, 115, 234-245. [CrossRef]

14. Pu, R.; Bell, S. A protocol for improving mapping and assessing of seagrass abundance along the West Central Coast of Florida using Landsat TM and EO-1 ALI/Hyperion images. ISPRS J. Photogramm. Remote Sens. 2013, 83, 116-129. [CrossRef] 
15. Lyons, M.B.; Phinn, S.R.; Roelfsema, C.M. Long term land cover and seagrass mapping using Landsat and object-based image analysis from 1972 to 2010 in the coastal environment of South East Queensland, Australia. ISPRS J. Photogramm. Remote Sens. 2012, 71, 34-46. [CrossRef]

16. Koedsin, W.; Intararuang, W.; Ritchie, R.J.; Huete, A. An Integrated Field and Remote Sensing Method for Mapping Seagrass Species, Cover, and Biomass in Southern Thailand. Remote Sens. 2016, 8, 292. [CrossRef]

17. Mumby, P.J.; Green, E.P.; Edwards, A.J.; Clark, C.D. Measurement of seagrass standing crop using satellite and digital airborne remote sensing. Mar. Ecol. Progr. Ser. 1997, 159, 51-60. [CrossRef]

18. Dierssen, H.; Zimmermann, R.C. Ocean colour remote sensing of seagrass and bathymetry in the Bahamas Banks by high-resolution airborne imagery. Limnol. Oceanogr. 2003, 48, 444-455. [CrossRef]

19. Schweizer, D.; Armstrong, R.A.; Posada, J. Remote sensing characterization of benthic habitats and submerged vegetation biomass in Los Roques Archipelago National Park, Venezuela. Int. J. Remote Sens. 2005, 26, 2657-2667. [CrossRef]

20. Knudby, A.; Nordlund, L. Remote sensing of seagrasses in a patchy multi-species environment. Int. J. Remote Sens. 2011, 32, 2227-2244. [CrossRef]

21. Wicaksono, P.; Hafizt, M. Mapping seagrass from space: Addressing the complexity of seagrass LAI mapping. Eur. J. Remote Sens. 2013, 46, 18-39. [CrossRef]

22. Hill, V.J.; Zimmermann, R.C.; Bissett, W.P.; Dierssen, H.; Kohler, D.D.R. Evaluating Light Availability, Seagrass Biomass, and Productivity Using Hyperspectral Airborne Remote Sensing in Saint Joseph's Bay, Florida. Estuar. Coasts 2014, 37, 1467-1489. [CrossRef]

23. Hedley, J.; Russell, B.; Randolph, K.; Dierssen, H. A physics-based method for the remote sensing of seagrasses. Remote Sens Environ. 2016, 174, 134-147. [CrossRef]

24. Dekker, A.G.; Phinn, S.R.; Anstee, J.; Bissett, P.; Brando, V.E.; Casey, B.; Fearns, P.; Hedley, J.; Klonowski, W.; Lee, Z.P.; et al. Intercomparison of shallow water bathymetry, hydro-optics, and benthos mapping techniques in Australian and Caribbean coastal environments. Limnol. Oceanogr. Methods 2011, 9, 396-425. [CrossRef]

25. Lee, Z.P.; Carder, K.L.; Mobley, C.D.; Stewart, F.G.; Patch, J.S. Hyperspectral remote sensing for shallow waters: 2. Deriving bottom depths and water properties by optimization. Appl. Opt. 1999, 38, 3831-3843. [CrossRef] [PubMed]

26. Zoffoli, M.L.; Frouin, R.; Kampel, M. Water column correction for coral reef studies by remote sensing. Sensors 2014, 14, 16881-16931. [CrossRef] [PubMed]

27. Lyzenga, D.R. Passive remote sensing techniques for mapping water depth and bottom features. Appl. Opt. 1978, 17, 379-383. [CrossRef] [PubMed]

28. Lyzenga, D.R. Remote sensing of bottom reflectance and water attenuation parameters in shallow water using aircraft and Landsat data. Int. J. Remote Sens. 1981, 2, 71-82. [CrossRef]

29. Mumby, P.J.; Clark, C.D.; Green, E.P.; Edwards, A.J. Benefits of water column correction and contextual editing for mapping coral reefs. Int. J. Remote Sens. 1998, 19, 203-210. [CrossRef]

30. Lesser, M.; Mobley, C. Bathymetry, water optical properties, and benthic classification of coral reefs using hyperspectral remote sensing imagery. Coral Reefs 2007, 26, 819-829. [CrossRef]

31. Mobley, C.D.; Sundman, L.K.; Davis, C.O.; Bowles, J.H.; Downes, T.V.; Leathers, R.A.; Montes, M.J.; Bissett, W.P.; Kohler, D.D.R.; Reid, R.P.; et al. Interpretation of hyperspectral remote-sensing imagery by spectrum matching and look-up tables. Appl. Opt. 2005, 44, 3576-3592. [CrossRef] [PubMed]

32. Maritorena, S.; Morel, A.; Gentili, B. Diffuse reflectance of oceanic shallow waters: Influence of water depth and bottom albedo. Limnol. Oceanogr. 1994, 39, 1689-1703. [CrossRef]

33. Lee, Z.; Carder, K.L.; Hawes, S.K.; Steward, R.G.; Peacock, T.G.; Davis, C.O. Model for the interpretation of hyperspectral remote-sensing reflectance. Appl. Opt. 1994, 33, 5721-5732. [CrossRef] [PubMed]

34. Mishra, D.; Narumalani, S.; Rundquist, D.; Lawson, M. High-resolution Ocean Color Remote Sensing of Benthic Habitats: A Case Study at the Roatan Island, Honduras. IEEE Trans. Geosci. Remote Sens. 2005, 43, 1592-1604. [CrossRef]

35. Mishra, D.; Narumalani, S.; Rundquist, D.; Lawson, M.; Perk, R. Enhancing the detection and classification of coral reef and associated benthic habitats: A hyperspectral remote sensing approach. J. Geophys. Res. 2007, 112, C08014. [CrossRef]

36. Minghelli-Roman, A.; Dupouy, C. Correction of water column attenuation: Application to the seabed mapping of the lagoon of New Caledonia using MERIS images. IEEE J. Sel. Top. Appl. Earth Observ. Remote Sens. 2014, 7, 2619-2629. [CrossRef] 
37. Pu, R.; Bell, S.; English, D. Developing hyperspectral vegetation indices for identifying seagrass species and cover classes. J. Coast. Res. 2015, 31, 595-615. [CrossRef]

38. Misbari, S.; Hashim, M. Change Detection of Submerged Seagrass Biomass in Shallow Coastal Water. Remote Sens. 2016, 8, 200. [CrossRef]

39. Werdell, P.J.; Roesler, C.S. Remote assessment of benthic substrate composition in shallow waters using multispectral reflectance. Limnol. Ocenaogr. 2003, 48, 557-567. [CrossRef]

40. Hedley, J.D.; Harborne, A.R.; Mumby, P.J. Simple and robust removal of sun glint for mapping shallow-water benthos. Int. J. Remote Sens. 2005, 26, 2107-2112. [CrossRef]

41. Pope, R.M.; Fry, E.S. Absorption spectrum $(380-700 \mathrm{~nm})$ of pure water. II. Integrating cavity measurements. Appl. Opt. 1997, 36, 8710-8723. [CrossRef] [PubMed]

42. Morel, A. Optical properties of pure water and pure sea water. In Optical Aspects of Oceanography; Jerlov, N.G., Steemann-Nielsen, E., Eds.; Academic Press: New York, NY, USA, 1974; pp. 1-24.

43. Toming, K.; Kutser, T.; Uiboupin, R.; Arikas, A.; Vahter, K.; Paavel, B. Mapping Water Quality Parameters with Sentinel-3 Ocean and Land Colour Instrument imagery in the Baltic Sea. Remote Sens. 2017, 9, 1070. [CrossRef]

44. Möller, T.; Kotta, J.; Martin, G. Effect of observation method on the perception of community structure and water quality in a brackish water ecosystem. Mar. Ecol. 2009, 30, 105-112. [CrossRef]

45. Stumpf, R.P.; Holderied, K.; Sinclair, M. Determination of water depth with high resolution satellite imagery over variable bottom types. Limnol. Oceanogr. 2003, 48, 547-556. [CrossRef]

46. Mobley, C.D. Estimation of the remote-sensing reflectance from above-surface measurements. Appl. Opt. 1999, 38, 7442-7455. [CrossRef] [PubMed]

47. Kirk, J.T.O. Light and Photosynthesis in Aquatic Ecosystems, 2nd ed.; Cambridge University Press: Cambridge, UK, 1994.

48. Gordon, H.R.; Brown, O.B.; Evans, R.H.; Brown, J.W.; Smith, R.C.; Baker, K.S.; Clark, D.K. A semianalytic radiance model of ocean color. J. Geophys. Res. 1988, 93, 10909-10924. [CrossRef]

49. Vahtmäe, E.; Kutser, T.; Martin, G.; Kotta, J. Feasibility of hyperspectral remote sensing for mapping benthic macroalgal cover in turbid coastal waters-A Baltic Sea case study. Remote Sens. Environ. 2006, 101, 342-351. [CrossRef]

50. Kutser, T.; Vahtmäe, E.; Martin, G. Assessing suitability of multispectral satellites for mapping benthic macroalgal cover in turbid coastal waters by means of model simulations. Estuar. Coast. Shelf Sci. 2006, 67, 521-529. [CrossRef]

51. Vahtmäe, E.; Kutser, T. Airborne mapping of shallow water bathymetry in the optically complex waters of the Baltic Sea. J. Appl. Remote Sens. 2016, 10, 025012. [CrossRef]

52. Vahtmäe, E.; Paavel, B.; Kutser, T. How much benthic information can be retrieved with hyperspectral sensor from the optically complex coastal waters? J. Appl. Remote Sens. 2020, 14, 016504. [CrossRef]

53. Vahtmäe, E.; Kutser, T.; Kotta, J.; Pärnoja, M.; Möller, T.; Lennuk, L. Mapping Baltic Sea shallow water environments with airborne remote sensing. Oceanology 2012, 52, 803-809. [CrossRef]

54. Armstrong, R.A. Remote sensing of submerged vegetation canopies and biomass estimation. Int. J. Remote Sens. 1993, 14, 621-627. [CrossRef]

55. Kutser, T.; Hiire, M.; Metsamaa, L.; Vahtmäe, E.; Paavel, B.; Aps, R. Field measurements of spectral backscattering coefficient of the Baltic Sea and boreal lakes. Boreal Environ. Res. 2009, 14, 305-312.

56. Kotta, J.; Remm, K.; Vahtmäe, E.; Kutser, T.; Orav-Kotta, H. In-air spectral signatures of the Baltic Sea macrophytes and their statistical separability. J. Appl. Remote Sens. 2014, 8, 083634. [CrossRef]

57. Purkis, S.J.; Pasterkamp, R. Integrating in situ reef-top reflectance spectra with Landsat TM imagery to aid shallow-tropical benthic habitat mapping. Coral Reefs 2004, 23, 5-20. [CrossRef]

58. Andrefouet, S.; Zubia, M.; Payri, C. Mapping and biomass estimation of the invasive brown algae Turbinaria ornata (Turner) J. Agardh and Sargassum mangarevense (Grunow) Setchell on heterogeneous Tahitian coral reefs using 4-meter resolution IKONOS satellite data. Coral Reefs 2004, 23, 26-38. [CrossRef]

(C) 2020 by the authors. Licensee MDPI, Basel, Switzerland. This article is an open access article distributed under the terms and conditions of the Creative Commons Attribution (CC BY) license (http://creativecommons.org/licenses/by/4.0/). 